\title{
O papel da memória discursiva em manchetes que desmentem notícias sobre covid-19
}

\author{
Gabriel Guimarães Alexandre*
}

\section{Resumo}

A pandemia de covid-19 trouxe-nos um contexto de exceção. Restrições impostas à sociedade foram aplicadas por governos de diferentes partes do mundo, gerando dificuldades, por exemplo, de escolha entre ter privacidade de dados ou saúde prometida por vigilância biométrica (HARARI, 2020). Como "resposta" à disseminação de fake news - não só sobre a doença, mas também sobre outros temas - as agências de fact-checking (PANGRAZIO, 2018; SPINELLI, SANTOS, 2018) surgem com o objetivo de verificá-las, classificando-as em "verdadeiras" ou "falsas", segundo gradação. Quando publicam a checagem realizada, as agências utilizam manchetes que desmentem as notícias. Entre os padrões linguísticos observados, a negação é bastante frequente nas manchetes verificadas em mídias sociais. Por ser um índice de implícito, está presente no enunciado para produzir sentido: a memória discursiva é, pois, um modo de compreender o estatuto dos implícitos (ACHARD, 1999; PÊCHEUX, 1999). Logo, partimos da hipótese de que a prática de estruturar a negação, nas manchetes analisadas, pode fazer emergir questões interlocutivas via evocação de certa memória discursiva. Com base em pressupostos teórico-metodológicos dos estudos de letramentos (New Literacy Studies) e da Análise do Discurso francesa, este trabalho objetivou analisar o papel da memória discursiva em 68 manchetes publicadas em março de 2020 por duas agências ("Chequeado" e "Agência

\footnotetext{
Universidade Estadual Paulista (UNESP/São José do Rio Preto). Mestre em Estudos Linguísticos (2020) e Graduado em Letras/ Espanhol (2018) pela mesma instituição. ORCID: https://orcid.org/0000-0002-1432-1118.
} 
Lupa"), as quais desmentem notícias sobre covid-19 em mídias sociais. Os resultados obtidos permitiram identificar três estruturas de negação frequentes nas manchetes e parecem confirmar a hipótese de partida, contribuindo com os estudos de letramentos, quanto à formação do leitor em tempos de pandemia.

Palavras-chave: Letramentos digitais. Desordem informacional. Memória discursiva. Manchetes.

\title{
The Hole of Discursive Memory in Headlines That Deny News About covid-19
}

\begin{abstract}
The covid-19 pandemic brought us an exceptional context. Governments applied restrictions imposed in our society from different parts of the world, generating difficulties, for example, in choosing between having data privacy or health promised by biometric surveillance (HARARI, 2020). As a "answer" to the dissemination of fake news - not only about the disease, but also about other topics - the fact-checking agencies (PANGRAZIO, 2018; SPINELLI, SANTOS, 2018) arise in order to verify them, classifying news in "true" or "false", according to gradation. When publishing the check carried out, the agencies use headlines that belie the news. Among the linguistic patterns observed, denial structures is quite frequent in the headlines seen on social media. As an index of the implicit, it is present in the discourse to produce meaning: the discursive memory is, therefore, a way of understanding the status of the implicit (ACHARD, 1999; PECCHEUX, 1999). Therefore, our hypothesis is that the practice of structuring the denial, in the analyzed headlines, can raise interlocutive questions through the evocation of a certain discursive memory.
\end{abstract}


Based of theoretical-methodological assumptions of New Literacy Studies and French Discourse Analysis, this paper aimed to analyze the role of discursive memory in 68 headlines, published in March 2020 by two agencies ("Chequeado" and "Agência Lupa"), which deny news about covid-19 on social media. The results obtained allowed to discover three frequent denial structures in the headlines and seem to confirm the starting hypothesis, contributing to literacy studies, regarding reader training in pandemic times.

Keywords: Digital literacies. Informational disorder. Discursive memory. Headlines.

Recebido em: 06/07/2021 // Aceito em: 10/09/2021. 


\section{Introdução ${ }^{1}$}

Em 31 de dezembro de 2019, a Organização Mundial da Saúde (OMS) foi informada a respeito de casos de "pneumonia viral" (até então de causa desconhecida) detectada na cidade de Wuhan, província de Hubei, na China. ${ }^{2}$ Tratava-se de uma doença - covid-193 - causada por um novo coronavírus, denominado Sars-CoV-2. A partir de notícias sobre os primeiros grupos que se contagiaram com o vírus e, posteriormente, sobre a rápida disseminação em países vizinhos à China, a situação foi acompanhada diariamente. Tomando proporções pandêmicas, no momento da escrita deste artigo, temos cerca de 183 milhões de casos detectados ao redor do globo com quase 4 milhões de mortes confirmadas. ${ }^{4}$

No caso do Brasil, as primeiras ações ligadas à pandemia de covid-19 começaram em fevereiro, a partir da repatriação dos brasileiros que viviam em Wuhan, cidade epicentro da infecção. Para ser mais exato, em 26 de fevereiro, o primeiro caso de coronavírus no Brasil foi confirmado - um homem de 61 anos que tinha voltado de viagem da Itália. ${ }^{5}$ A partir dessa infecção, os números não pararam de crescer, colocando o Brasil como terceiro país com mais casos de infecção por coronavírus do mundo - cerca de 8 milhões já foram contaminados e mais de 200 mil mortes já foram confirmadas - atrás somente da Índia e dos Estados Unidos.

\footnotetext{
1 O presente trabalho foi realizado com apoio da Coordenação de Aperfeiçoamento de Pessoal de Nível Superior (CAPES) do Brasil - Código de Financiamento 001, no âmbito da Rede de Pesquisa Internacional Literacies in Different Fields of Knowledge do Programa CAPES PrInt UNESP (processo CAPES/AUXPE n. 88881.310711/2018-01).

2 Disponível em: https:/www.who.int/emergencies/diseases/novel-coronavirus-2019/situation-reports. Acesso em: 3 jul. 2021.

3 Covid-19 é acrônimo para Coronavirus Disease (doença do coronavírus). O número "19" é uma referência ao ano de 2019, quando os primeiros casos do novo coronavírus foram notificados em Wuhan, província de Hubei, China.

4 Disponível em: https://coronavirus.jhu.edu/map.html. Acesso em: 3 jul. 2021.

5 Disponível em: https://www.sanarmed.com/linha-do-tempo-do-coronavirus-no-brasil. Acesso em: 3 jul. 2021.
} 
É sabido que esse acontecimento - o cenário pandêmico em diferentes partes do planeta - produziu uma quantidade significativa de textos: desde compartilhamento de notícias e de comentários em redes sociais, como Facebook, Twitter, Instagram e Whatsapp, até produção de notícias pela imprensa mundial e seu necessário trabalho de desmistificação de informações a respeito da circulação e das características do vírus. Um fenômeno batizado pelo diretor-geral da OMS, Tedros Ghebreyesus, de "infodemia" colocou em evidência o comportamento "viral" pelo qual a disseminação de notícias falsas/enganosas a respeito da covid-19 tem sido reconhecida. $\mathrm{Na}$ dinâmica da desinformação, esse comportamento está associado a graves problemas em diferentes esferas de atividade humana, como relações diplomáticas, turismo, eventos, além de impactos sobre a economia. Restrições impostas à sociedade foram aplicadas por governos de diferentes partes do mundo, gerando dificuldades, por exemplo, de escolha entre ter privacidade de dados ou saúde prometida por vigilância biométrica (HARARI, 2020). A respeito do aspecto econômico, ainda, o chanceler italiano, Luigi Di Maio, afirmou, durante entrevista, que "a infodemia [...] [está] prejudicando a economia e a reputação do país [...]" ${ }^{6}$ Como possível "resposta" a essa disseminação de notícias falsas - não apenas sobre a covid-19, mas também outras -, as agências de fact-checking (checagem de fatos) (NYHAN; REIFLER, 2014; MONNERAT, 2017; PANGRAZIO, 2018; SPINELLI; SANTOS, 2018) surgem com o objetivo de verificar fatos noticiados, classificando-os em "verdadeiros" ou "falsos", segundo uma gradação. Concebida como "missão de trabalho" por diferentes jornalistas, há forte demanda dessa prática,

6 Disponível em: https://www.bbc.com/portuguese/internacional-51666948. Acesso em: 3 jul. 2021. 
sobretudo em contexto de pós-verdades, contexto marcado por "circunstâncias nas quais fatos objetivos são menos influentes na opinião pública do que apelos à emoção e à crença pessoal." (MCINTYRE, 2018, p. 5). ${ }^{7}$

De acordo com Santos e Spinelli (2018), citando Monnerat (2017), a prática de fact-checking aumentou, a partir dos anos 2000, com o cenário de corridas eleitorais em diferentes países, tendo tido reconhecimento e audiência internacionais, também por meio de premiações. As autoras afirmam que o reconhecimento da prática levou à criação de uma rede internacional - International Factchecking Network (IFCN, do Poynter Institute) -, que oferece código de princípios éticos e conferências globais anuais, com o objetivo de fomentar discussões a respeito da checagem de notícias no mundo todo. É sabido, também, que essa prática, iniciada nos Estados Unidos, incentivou outros países no combate à disseminação de notícias falsas. A "Agência Lupa", do Brasil, e a "Chequeado", da Argentina, são outros exemplos de pioneirismo dessa prática.

Elegemos esses dois países latino-americanos não somente pelo pioneirismo com o trabalho desse tipo nos respectivos países e não só por ambas terem a certificação da IFCN (colocando-as como agências de metodologias já consolidadas), mas também pela consideração de que, na região das Américas (América do Norte, América Central e América do Sul), $81 \%$ do total de 1.04 bilhão de habitantes do continente encontram-se em área urbanizada ou em processo de urbanização; $76 \%$ dessa população têm acesso à internet, e, desse grupo, 67\% são usuários ativos em mídias sociais. Em comparação com o restante do planeta, a região das Américas é a mais engajada em mídias sociais. ${ }^{8}$

\footnotetext{
7 Nossa tradução para "circumstances in which objetive facts are less influential in shaping public opinion than appeals to emotion and personal belief.".

8 Esses dados, de modo detalhado, também podem ser consultados no mais recente relatório da agência We Are Social, disponível em https://wearesocial.com/digital-2020. Acesso em: 5 jul. 2021.
} 
Trata-se, portanto, de dois países inscritos num cenário que permite comparações importantes a respeito de como a desinformação é tratada e textualizada por essas agências, quando o compromisso é desmentir fatos a que elas têm acesso, ou que são para elas trazidos em busca da "verdade" ou da "mentira". Destacamos, ainda, que, apesar de o inglês ser considerado uma língua "universal" (CRYSTAL, 2003), o português e o espanhol são falados em mais de dez países, o que mostra a influência dessas línguas no globo. ${ }^{9}$

Quando as agências de checagem publicam o resultado de suas investigações em seus sites, as agências lançam mão de manchetes que buscam, na maior parte das vezes, desmentir as notícias. Entre os padrões observados, a negação é bastante frequente nas manchetes verificadas em mídias sociais. Por ser um índice de implícito, está presente no enunciado para produzir sentido: a memória discursiva é, portanto, um modo de compreender o estatuto do implícito (ACHARD, 1999; PÊCHEUX, 1999). Logo, partimos da hipótese de que a prática de estruturar a negação, nas manchetes em análise, pode fazer emergir questões interlocutivas via evocação de certa memória discursiva. Por essa razão, neste trabalho, a proposta é refletir a respeito do papel da memória discursiva (cf. "Fundamentos teóricos") em manchetes publicadas por duas agências de factchecking no contexto das mídias sociais, observando-se as repetidas negações presentes nos títulos das notícias publicadas pelas agências no mês de março de 2020 .

A escolha de observar essa marca linguístico-discursiva justifica-se por sua frequente presença na maior parte das manchetes publicadas pelas agências em questão no que diz

9 Disponível em: https://www.vistawide.com/languages/top_30_languages.htm. Acesso em: 5 jul. 2021. 
respeito às fake news em mídias sociais. Assim, apresentamos, inicialmente, considerações a respeito do fact-checking como prática letrada digital, para aprofundarmos a respeito do conceito de memória discursiva. Em seguida, apresentamos os resultados obtidos para discussão dos dados. Concluímos, portanto, não apenas com perspectivas futuras de investigação, mas também com a tentativa de contribuir com os estudos de letramentos digitais quanto à formação do leitor em tempos de pandemia.

\section{Fundamentos teóricos}

Notícias falsas ou enganosas têm sido concebidas, no âmbito de estudos como os de Comunicação, como parte de um fenômeno mais amplo, chamado "desordem informacional" ou "desinformação" (MARTENS et al., 2018; WARDLE; DERAKHSHAN, 2017; MARWICK; LEWIS, 2017; LEWANDOWSKY et al., 2012). Por não se referirem, restritamente, ao falseamento deliberado de informação, os autores mencionados distinguem o fenômeno entre (i) misinformation, que se refere ao compartilhamento de informação falsa, sem pretensão de causar dano; (ii) disinformation, que se refere ao compartilhamento de informação falsa, com pretensão de causar dano e (iii) mal-information, que se refere ao compartilhamento de uma informação mais ou menos falsa, com pretensão de causar dano a pessoas, organizações ou países. Os autores distinguem esse fenômeno com o objetivo de problematizar essas notícias, assumindo que há sempre uma intenção - deliberada ou não - de um "agente" para causar dano por meio da veiculação de "mensagem" falsa. 
É importante destacar que "mensagem", para Wardle e Derakhshan (2017), é tomada numa perspectiva de elementos de propagação - tais como resposta emotiva, componente visual forte, narrativa forte e repetição. Contudo, mensagem pode ser entendida numa diferenciação entre informação e notícia. Longhi (2015) argumenta que a informação tem uma constituição que lhe é "própria" - dar forma à matéria, como descrição, concretização, num sentido etimológico estrito -, mas se constitui na correlação com alguém, como informação re-conhecida - e não "transmitida" - pela pessoa que a recebeu. Tandoc Jr., Lim e Ling (2018), por sua vez, consideram que a notícia é, ao mesmo tempo, produto do jornalismo - porque se comprometeria a produzir informação independente, confiável, precisa e compreensiva - e resultado de uma construção social. Sobre este último aspecto, os autores ressaltam que todo jornalista opera com julgamento subjetivo na escolha do que incluir na, ou excluir da informação. Por essa razão, segundo os autores, "notícias são vulneráveis não apenas às preferências dos jornalistas (White 1950), mas também a forças externas, tais como governo, público e anunciadores [...]" (SHOEMAKER; REESE, 2013 apud TANDOC JR.; LIM; LING, 2018, p. 140). ${ }^{10}$ Dessa forma, não se trata de dizer que "notícia" veicula "informação" verdadeira ou falsa, mas de dizer que tal verificação só pode ser percebida pela composição entre os dois componentes, além de incluir fatores sócio-históricos, políticos e culturais.

Toda notícia é veiculada por meio de textos. Nos estudos de letramentos (New Literacy Studies), Lankshear e Knobel $(2006,2011)$ afirmam que o modo como as pessoas mobilizam diferentes valores e prioridades em práticas sociais

10 Nossa tradução para "news is vulnerable not only to journalists' own preferences (White 1950), but also to external forces, such as the government, audiences, and advertisers". 
de leitura e escrita com uso de tecnologias digitais - ditos Novos Letramentos - diz respeito à maneira como produzem significados. Práticas sociais são entendidas como "modos socialmente reconhecidos nos quais pessoas geram, comunicam, negociam significados, enquanto membros de Discursos, por meio de textos codificados." (LANKSHEAR; KNOBEL, 2011, p. 33). ${ }^{11}$ Por "textos codificados", os autores fazem referência ao caráter "congelado" de sua apreensão, sendo "transportáveis" para outros contextos.

Argumentam que "bloggar", escrever fanfics, produzir mangás e memes, editar imagens, podcasts ou vodcasts e jogos também são práticas sociais letradas, que se relacionam a um novo ethos correspondente à ideia de uma comunidade mais participativa, colaborativa e distribuída, a qual surge de uma "ruptura do espaço", associada, por sua vez, a mudanças significativas em sociedades. Essa ruptura tem sido acompanhada pelo surgimento de um novo paradigma mais "distribuído" e "colaborativo", mesmo que os autores sejam críticos quanto a desigualdades sociais desses espaços.

A emergência de novas práticas letradas em sociedades contemporâneas que utilizam tecnologias digitais de informação e comunicação tem suscitado debates em torno dos diferentes letramentos que estão em jogo no processo comunicativo, conforme célebre manifesto do "Grupo de Nova Londres", publicado há 24 anos, em 1996. De acordo com o grupo, a pedagogia dos "multiletramentos" considera a crescente variedade de formas de (composição de) textos. A integração entre diferentes modos semióticos (KRESS, 2009) ${ }^{12}$ na

\footnotetext{
11 Nossa tradução para "socially recognized ways in which people generate, communicate, and negotiate meanings, as members of Discourses, through the medium of encoded texts".

12 Um modo semiótico pode ser definido como "um recurso socialmente formado e culturalmente dado para produção de sentido." (KRESS, 2009, p. 54, tradução nossa). Usado para representar "algo" no plano do simbólico, o modo só pode ser bem
} 
constituição do que é texto nas sociedades atuais pode explicar fenômenos ligados à convivência de diferentes processos de ação do signo (visual, verbal, sonoro). Essa é a composição de textos que encontramos em agências de checagem de fatos que buscam desmentir uma notícia de mídia social. Assim, o trabalho de verificação de notícias também pode ser considerado uma prática letrada digital.

Do que precede, é necessário verificar em que medida a memória discursiva pode ter um importante papel nessas práticas letradas digitais. Evocamos o conceito a partir da Análise do Discurso francesa (doravante AD). Referida, muitas vezes, como "disciplina do entremeio" (ORLANDI, 2009), uma vez que articula conceitos de três principais campos do saber (a Linguística, a Psicanálise e a História), a AD compreende o sistema da língua e sua gramática na relação indissociável com as condições de produção sócio-históricas de que são constituídas. Desse modo, "discurso" é um conceito que diz respeito aos efeitos de sentido entre interlocutores (PÊCHEUX, 1990), o que implica que o dizer emerge em função de dadas condições sóciohistóricas de produção - as quais, por sua vez, possibilitam a emergência desse dizer e do próprio sujeito.

Sujeito e discurso, dessa perspectiva, são constitutivamente heterogêneos e produtos do interdiscurso (AUTHIER-REVUZ, 1990; MAINGUENEAU, [1995]/2008). ${ }^{13}$ O interdiscurso é compreendido como "espaço de trocas entre vários discursos convenientemente escolhidos [...]" (MAINGUENEAU, 2008, p. 20). Ele se faz ver nas contradições, nos embates ou nas

compreendido a depender da configuração convencional de dadas sociedades.

13 A data entre colchetes indica o ano de publicação original da obra, que só será indicada na primeira citação da obra neste texto. Nas seguintes, será registrada apenas a data de edição consultada pelos autores. 
aproximações entre dois ou mais discursos, ou até na exposição pretensiosa de um único discurso - que pode recuperar outro, por oposição ou por antecipação, historicamente.

$\mathrm{Na}$ rede interdiscursiva, os discursos se repetem ou retomam enunciados "já ditos", "esquecidos" ou "por dizer" (via antecipação, por exemplo). Essa propriedade, que leva em conta implícitos presentes no enunciado para produzir sentido, fez com que a $\mathrm{AD}$ lançasse mão do conceito de "memória discursiva"14 - diferentemente daquela individual, no sentido psicologista, trata-se de uma memória social e coletiva, inscrita em práticas, memória construída do historiador (PECHEUX, 1999). Assim, elegemos a negação, que apresenta certa regularidade nas manchetes das notícias verificadas em mídias sociais, como marca linguístico-discursiva em que o papel da memória pode estar atuando, uma vez que falar de memória é falar "do estatuto dos implícitos [...]” (ACHARD, 1999, p. 11). Os implícitos trazidos pela negação podem ser interpretados como possíveis sintagmas "cujo conteúdo é memorizado e cuja explicitação (inserção) constitui uma paráfrase controlada por esta memorização [...]" (ACHARD, 1999, p. 12).

Embora nem sempre recuperável, Achard (1999) argumenta que o implícito, do ponto de vista discursivo, trabalha sobre a base de um imaginário que o representa como memorizado. Desse modo, o discurso, ao pressupor o implícito, possibilita - apesar a sua (re)construção sob a restrição "no vazio" (a expressão é do autor) -, as formas que permitem sua inserção na paráfrase. Isso porque, segundo o autor, a explicitação dos implícitos, em

\footnotetext{
14 É sabido que Paveau (2013) procede a uma extensa revisão bibliográfica a respeito do conceito de memória discursiva, realocando-o não apenas na reflexão da própria de noção de interdiscurso (tratando, pois, de uma memória que é interdiscursiva), mas também introduzindo importantes conceitos a partir da assunção de uma cognição social. Neste trabalho, optamos por trabalhar com a noção clássica de memória discursiva, com o objetivo de empreendermos uma aproximação inicial com o quadro teórico dos letramentos.
} 
geral, não é necessária e não faz falta, pois a paráfrase de sua explicitação aparece, antes, "como um trabalho posterior sobre o explícito do que como pré-condição [...]" (ACHARD, 1999, p. 13).

Logo, por ser a memória, como diz Pêcheux (1999, p. 52), uma "estruturação de materialidade discursiva complexa, estendida em uma dialética da repetição e da regularização [...]", a memória discursiva seria "aquilo que, face a um texto que surge como acontecimento a ler, vem estabelecer os 'implícitos' [...] de que sua leitura necessita: a condição do legível em relação ao próprio legível [...]" (PÊCHEUX,1999, p. 52). É considerando os implícitos "ausentes por sua presença" - a expressão é de Pêcheux - que observaremos, na repetição dessas estruturas de negação, "a formação de um efeito de série pelo qual uma 'regularização' (termo introduzido por P. Achard) se iniciaria." (PÊCHEUX, 1999, p. 52).

$\mathrm{Na}$ proposta de Ducrot (1988), de um ponto de vista semântico, o fenômeno das negações pode ser interpretado, psicanaliticamente, como negociação do ego entre as vontades libidinosas do id e a característica de censura do superego. Haveria, pois, em uma frase com negação, a voz do $i d$ (enunciado positivo) e a do superego (por meio do modificador "não"). Ela permite, portanto, "dizer coisas e ao mesmo tempo censurá-las [...]" (DUCROT, 1988, p. 23). Antes de enfocar um dos tipos de negação oferecidos pelo linguista, é importante uma ressalva entre quadros teóricos distintos. Fossey (2011) defende que essa ressalva consiste na noção de sentido e de sujeito. Segundo ela, para Ducrot, o sentido do enunciado é proposto na relação com a significação estrita da proposição em busca de argumentar. Para a $\mathrm{AD}$, entretanto, o sentido é da ordem do discurso, pois "não 
resulta apenas das estruturas da língua, mas da sua articulação com a história e com as ideologias [...]" (FOSSEY, 2011, p. 113). No caso da noção de sujeito, por nós evocada, é suficiente dizer que o sujeito, na $\mathrm{AD}$, "não é um sujeito livre e tático, mas está submetido às regras do posicionamento ao qual adere." (FOSSEY, 2011, p. 113). A noção de sujeito e de discurso assumidas neste trabalho não é aquela da perspectiva enunciativa de Ducrot, nem aquela subjacente às pesquisas em letramentos digitais; tratase de uma posição-sujeito, possibilidade de ocupação de uma posição discursiva.

O sujeito de enunciação, para Ducrot, segundo a organização de Fossey (2011), conta com as noções de sujeito empírico, locutor e enunciador. O sujeito empírico seria o equivalente literário do autor responsável pela produção do enunciado. O locutor, por sua vez, é aquele a quem é atribuída a responsabilidade pela enunciação por meio de marcas dêiticas inscritas no próprio enunciado - o correspondente literário, por exemplo, do narrador. O enunciador, então, é o ponto de vista decorrente de um enunciado, entendido, assim, como entidade abstrata que representa diferentes perspectivas enunciativas. Se, para nossa análise, elegemos um dos tipos de negação, a polêmica, é porque concordamos com Fossey (2011), no que diz respeito ao fato de que, nesse tipo de negação, é possível observar certo diálogo entre dois enunciadores que se recusam $\left(E_{1}\right.$ e $\left.E_{2}\right)$, entendidos como dois pontos de vista em confronto. Enquanto para Ducrot os enunciadores são entidades virtuais que manifestam pontos de vista no interior do enunciado, para a linguista esses "pontos de vista" podem ser interpretados como materialização de certos posicionamentos em dada formação discursiva. Enunciadores, seriam, portanto, "manifestação do Outro no discurso do Mesmo na forma de um simulacro [...]" (FOSSEY, 2011, p. 119). 
$\mathrm{Na}$ análise aqui proposta, tentaremos vincular os implícitos deixados pelos pontos de vista dos "enunciadores" a uma memória discursiva que pode condicionar o exercício, como diria Achard (1999), de uma regularidade enunciativa nessas práticas letradas digitais inscritas no contexto informacional. As razões dessas escolhas teóricas têm a ver com o fato de que, de nosso ponto de vista, compreender o fenômeno das notícias falsas ou enganosas requer a investigação de dimensões sócio-históricas e culturais que possibilitam sua emergência e disseminação.

\section{Procedimentos metodológicos}

O corpus deste trabalho é formado de 68 (sessenta e oito) manchetes de notícias, publicadas por duas agências de checagem de fatos durante o mês de março de 2020. Os critérios com base nos quais recolhemos as manchetes das notícias são: (i) agências eleitas por sua relevância sócio-histórica, política e cultural no pioneirismo dessa prática de checagem em seus países e pela intensa penetração em mídias sociais, característica que destaca os países da América em detrimento de outros, de outros continentes; (ii) notícias sobre covid-19 que tenham circulado em mídias sociais no mês de março de 2020. Dessa forma, excluímos desse corpus as notícias de caráter apresentativo (não checam nenhuma informação, mas informam mudanças, por exemplo no site, ou novidades da própria agência), as notícias checadas não relacionadas à covid-19 e, por fim, notícias que foram resultados de um convênio entre agências, como o projeto Latam Chequea. ${ }^{15}$

15 O projeto colaborativo Latam Chequea congregou editores e jornalistas de 17 meios de comunicação da América Latina e de países de outras regiões que se dedicaram à verificação de informações, buscando melhorar a qualidade do debate público com o compartilhamento de experiências e ferramentas. Suas verificações foram excluídas do nosso conjunto de manchetes porque 
É importante, ainda, localizar de que seções foram retiradas as notícias aqui escolhidas. Cada agência tem, na organização de seu site, uma seção específica (chamada de "guia") para análise de textos que circularam em redes sociais e suscitaram, por critérios de cada agência, atenção. Da agência argentina "Chequeado", com base na guia "\#FalsoEnLasRedes", foram selecionadas 20 notícias. Da agência brasileira "Agência Lupa", por sua vez, com base no marcador "\#VERIFICAMOS", foram selecionadas 48 notícias. O período eleito (mês de março de 2020) foi o que antecede a maioria do início dos isolamentos estritos nesses países. Logo, é a partir de março que notícias falsas ou enganosas a respeito da covid-19 foram disseminadas com mais frequência. Trata-se, portanto, de um recorte para uma análise quanti-qualitativa das estruturas de negação presentes nessas manchetes.

\section{Discussão dos resultados obtidos}

$\mathrm{Na}$ análise quantitativa das 68 manchetes, encontramos dois padrões de estruturas frequentes e em comum nas duas agências ("Fato X é incorreto" e "Fato X não é Y"). Embora a segunda estrutura não seja tão frequente na agência "Chequeado", deixaremos para outro momento a análise de outros padrões. Observemos a frequência obtida da análise de 20 manchetes dessa agência. 


\section{Tabela 1 - Estruturas de negação frequentes da agência "Chequeado"}

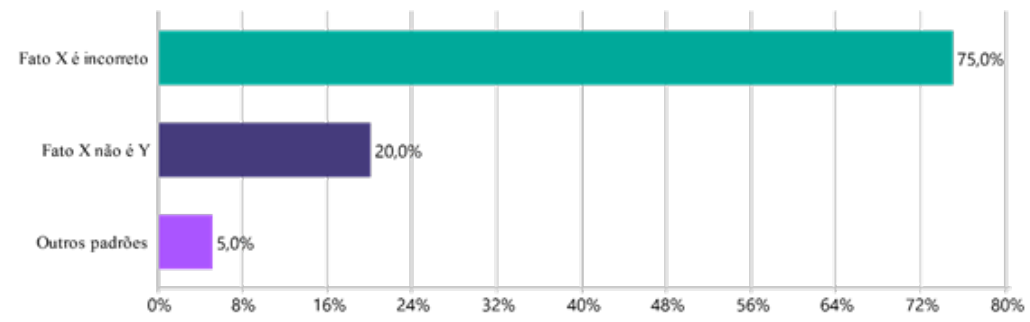

Fonte: elaborado pelo autor.

Em seguida, é necessário observar, também, a frequência obtida da análise de 48 manchetes da agência "Agência Lupa".

Tabela 2 - Estruturas de negação frequentes da agência "Agência Lupa"

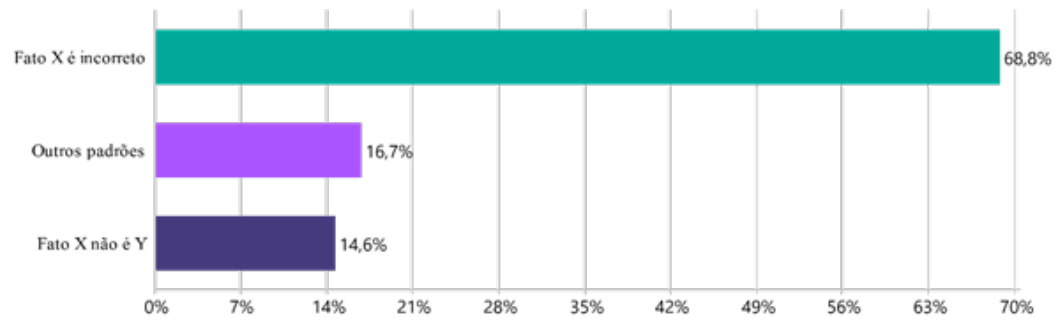

Fonte: elaborado pelo autor.

Podemos observar que a estrutura "Fato X é incorreto" é mais frequente nas duas agências (75\%, na "Chequeado", e 68,8\%, na "Agência Lupa"). A estrutura "Fato X não é Y" fica, somente na "Chequeado", em terceiro lugar de frequência. Exemplificaremos como tais estruturas aparecem. 
Figura 1 - Manchete publicada pela agência "Agência Lupa"

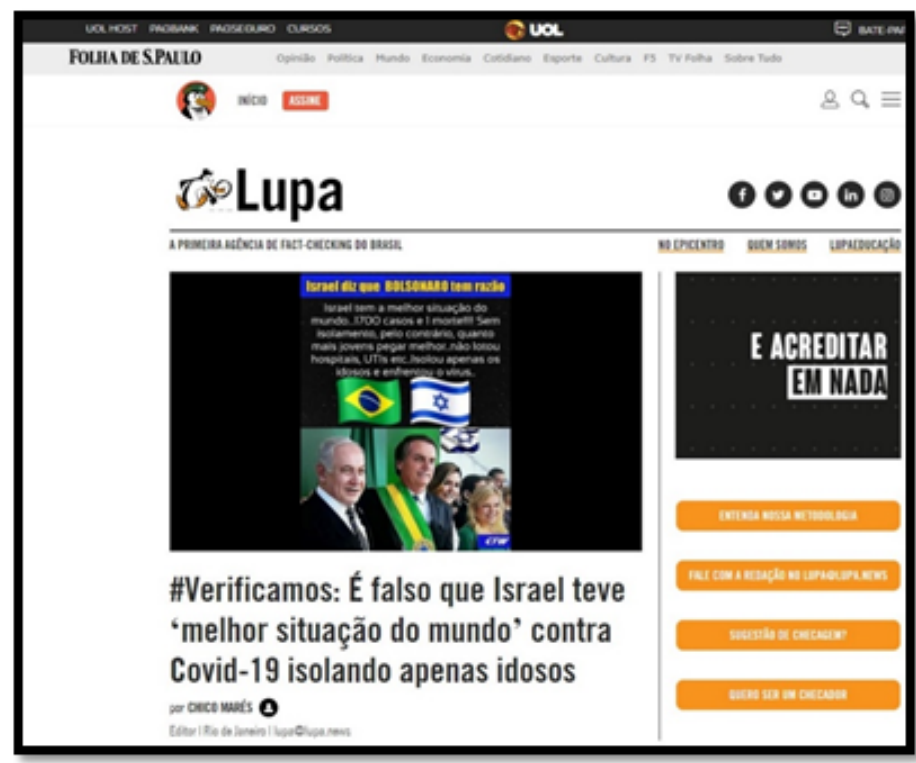

Fonte: Printscreen da tela da notícia.

É possível observar, na Figura 1, que, antes mesmo da manchete, há a imagem que foi analisada pela agência. Nessa composição verbo-visual, há uma foto do atual presidente da república Jair Bolsonaro (sem partido), ao lado do primeiroministro de Israel, Benjamin Netanyahu. O título diz "Israel diz que Bolsonaro tem razão", que, por uma relação metonímica entre o primeiro ministro e seu país, confere oficialidade ao que está sendo dito. Há uma série de informações falsas que são apuradas pelas agências. Vamos atentar somente à manchete propriamente dita: “\#Verificamos: É falso que Israel teve 'melhor situação do mundo' contra covid-19 isolando apenas idosos [...]". Nela, podemos observar a primeira estrutura de 
negação proposta ("Fato X é incorreto"), ${ }^{16}$ na qual é possível compreender a dinâmica dos enunciadores em confronto:

1) $E_{1}$ : Israel teve melhor situação do mundo contra covid-19 isolando apenas idosos.

$\mathrm{E}_{2}$ : refutação de $\mathrm{E}_{1}$ por meio da oração "É falso que".

Este exemplo é representativo do que acontece na maior parte das manchetes analisadas da primeira estrutura. O que ocorre é que o ponto de vista de $\mathrm{E}_{1}$ é quase sempre associado ao ponto de vista do "engano": não se trata de dizer que há "locutores" responsáveis ou correspondentes a esses posicionamentos, mas os posicionamentos do enunciador em questão são sempre aqueles contra os quais a agência busca desmentir. Assim, $E_{2}$ é, por sua vez, a materialização do posicionamento da agência que, em todos os casos, busca a estratégia da refutação de E1 para desmenti-lo por meio de, neste caso, uma introdução de oração ou do discurso relatado - mas há outros modos de refutá-lo.

Esse embate de pontos de vista acompanha a produção de sentido dos enunciados negativos. A interpretação de $\mathrm{E}_{2}$ como posicionamento da agência é possível não apenas porque esse tipo de estrutura é frequente nas publicações do mês escolhido, mas também porque o objetivo explicitado pela agência em seu site é o de estimular o debate público, utilizando-se de dados e informações precisas, baseados em fontes oficiais que precisam ser checadas. A manchete que quer desmentir a informação falsa busca, portanto, alinhar-se a essas expectativas registradas na própria metodologia de investigação de que lançam mão.

16 É importante dizer que optei por designar como "incorreto" aquelas tentativas de dizer por que determinado fato não é verdadeiro. Nas manchetes, aparecem, para somente oferecer exemplos, "É falso que", "Não existe", "É antigo/a", na "Agência Lupa", ou "Es falso que", "No hay pruebas de que", na "Chequeado". 
Observemos, agora, na Figura 2, a segunda estrutura de negação de que tratamos, mas na agência "Chequeado".

\section{Figura 2 - Manchete publicada pela agência "Chequeado"}

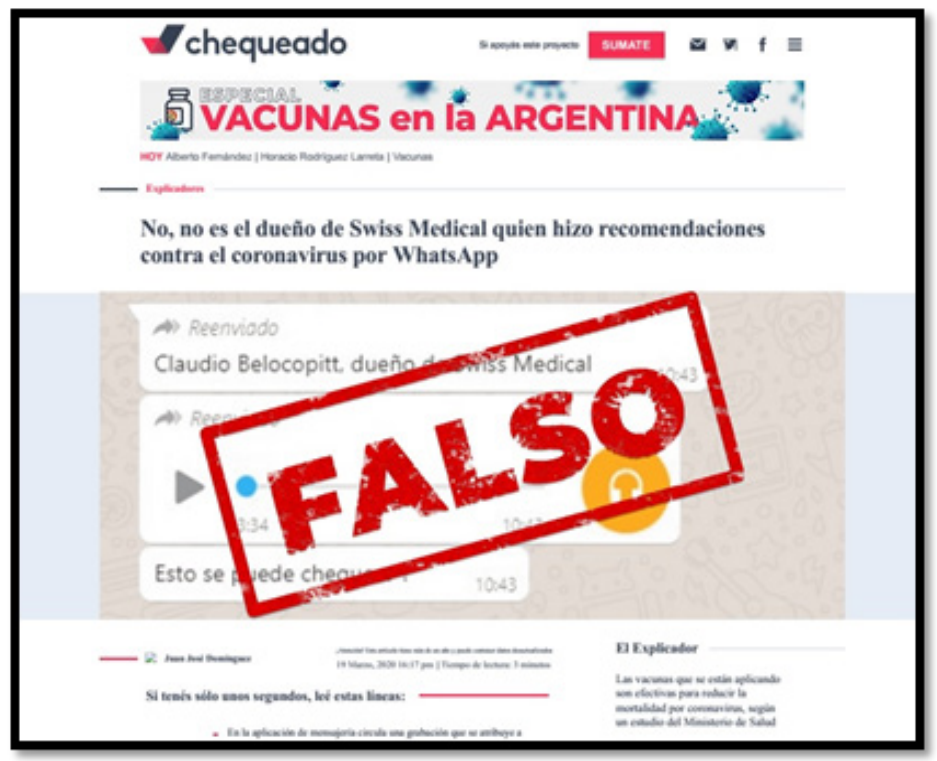

Fonte: Printscreen da tela da notícia.

Observamos, na Figura 2, textualização diferente do que acontece com relação à "Agência Lupa": a manchete é trazida antes mesmo da imagem. Quanto à imagem, podemos observar o que parece ser também o objeto de checagem que a agência busca desmentir. Trata-se do que parece ser um printscreen de uma conversa do aplicativo de mensagens WhatsApp. Um aspecto importante a ser observado é a indicação, feita pelo próprio aplicativo, de mensagem reenviada ("Reenviado"), indicando um movimento de propagação da notícia que, na realidade, é falsa, esforço de checagem reforçado por uma reprodução de superfície carimbada, de cor vermelha, indicando possivelmente os danos que aquela propagação pode causar em 
termos de qualificar o debate público, uma vez que qualificar o debate público é um objeto explícito da própria agência em seu site.

No que se refere à manchete, temos "No, no es el dueño de Swiss Medical quien hizo recomendaciones contra el coronavirus por WhatsApp". Nela, podemos observar a segunda estrutura de negação proposta ("Fato X não é Y"), compreendendo a seguinte dinâmica enunciativa:

2) $\mathrm{E}_{1}$ : Es eldueñode Swiss Medical quien hizorecomendaciones contra el coronavirus por WhatsApp.

$\mathrm{E}_{2}$ : refutação de $\mathrm{E}_{1}$ por meio da dupla aparição do modificador "No".

Da mesma forma que na primeira estrutura, exemplificada com a ocorrência da Figura 1, aqui $\mathrm{E}_{1}$ é quase sempre associado ao ponto de vista do "engano", pois a agência o prevê nas estruturas negativas utilizadas, para desmentir esse ponto de vista. $\mathrm{E}_{2}$, por sua vez, também acaba sendo a materialização do posicionamento da agência, que busca, nesse caso, a estratégia da refutação de $\mathrm{E}_{1}$ para desmenti-lo, utilizando duplamente o modificador "No".

Do que precede, a ocorrência dessas estruturas sintáticas de negação que buscam confrontar a posição enunciativa antagonista pode nos dizer muito quando adicionamos, agora, o problema da memória discursiva. Pelo caráter de repetição, comprovado pelas frequências obtidas, é possível, além de identificar o confronto entre esses dois enunciadores - que são relidos, nessas práticas letradas digitais, segundo confronto entre posicionamentos discursivos antagonistas, numa relação de negação polêmica -, 
propor a essas estruturas uma identificação de pergunta implícita, cuja resposta terá sempre seu lugar encontrado no corpo textual. À primeira estrutura ("Fato X é incorreto"), propomos a pergunta implícita "O que é correto?"; à segunda estrutura ("Fato X não é Y"), por sua vez, propomos a pergunta implícita "O que é, então?”. A partir dessas proposições, como explicar a existência dessas perguntas implícitas, que se fazem ouvir na cadeia das manchetes analisadas?

Como Achard (1999), ao analisar os implícitos emergidos a partir da palavra "crescimento" no domínio da Economia Política, podemos dizer que, no domínio da Desordem Informacional - campo que estuda a presença de desinformação em práticas letradas midiáticas/digitais -, percebemos que a falta de explicitação dessa pergunta não é, de início, sequer necessária, porque essa ausência "não faz falta, [uma vez que] a paráfrase da explicitação aparece antes como um trabalho posterior sobre o explícito do que como pré-condição.” (ACHARD, 1999, p. 13). Se, conforme o autor, o pressuposto é um consenso sobre o implícito como representação, essa representação só aparece porque é inscrita numa memória discursiva específica. Poderíamos dizer, nesta breve análise, que essa prática de estruturar a negação, de modo que uma pergunta fique implícita, retomaria um caráter constitutivo da linguagem em termos de sua interlocução - aquele em que um sujeito, ao desmentir um conteúdo proposicional dado, pode fazê-lo em busca de suscitar a vontade de verdade (FOUCAULT, [1970] 2014), ou seja, uma vontade de saber a resposta solicitada por um dado sujeito, coagindo-o a descobrir a verdade dos fatos.

Assim, quando o sujeito é interpelado por essas estruturas de negação, pode recuperar, via atravessamento dessa memória 
de interlocução, uma necessidade de obter uma resposta para estabilizar a pergunta implícita que surgiu a partir do enunciado desmentido. Essa interpretação pode ser possível, porque "os operados linguageiros só funcionam com relação à imersão em uma situação [...]" (ACHARD, 1999, p. 14). Só podemos supor que essa memória funcionaria junto aos implícitos identificados, porque essa prática, mesmo que "recuperada anteriormente", só pode ser evocada em função "[d]o discurso concreto face ao qual nos encontramos." (ACHARD, 1999, p. 14.).

A regularidade dessas estruturas (sobretudo da primeira) é de natureza, é claro, hipotética: o implícito implicado nessa regularidade pode permitir ao sujeito criar um inventário dessas estruturas e enquadrar as perguntas implícitas naquilo para o que não foram requisitadas, mas percebidas justamente por aquilo que foi enunciado. Somemos isso ao fato de que, como ambas as agências - "Agência Lupa" e "Chequeado" - pretendem desmentir enunciados que circulam nas redes, as manchetes recuperarão essa memória para tentar assegurar - porque sempre é hipótese - uma garantia de propagação após a publicação de seus serviços. Num cenário de infodemia, a recorrência de tal estratégia pode representar essa aproximação com outras práticas que, via memória, são recuperadas pelos sujeitos leitores, inscritos sócio-historicamente no cenário pandêmico em que estamos vivendo.

\section{Considerações finais}

O objetivo, com as análises empreendidas, foi mostrar como a recuperação de uma memória discursiva do desmentir pode ter um papel importante na explicitação de perguntas implícitas que 
funcionam de modo argumentativo nas manchetes das agências eleitas. Num contexto marcado pela pandemia de covid-19 e pela intensa penetração de usuários em mídias sociais, o papel da memória intervém como possibilidade de que certos leitores se engajem nas manchetes solicitadas e sejam desmentidos por outro grupo de leitores, por meio de "recordação" de práticas interlocutivas com o objetivo de interpelar o outro para obtenção de uma necessidade de resposta.

Essa estratégia é identificada e não é aleatória ou acidental. O contexto de pós-verdades a que estamos sujeitos nesse cenário informacional, como produtores e leitores, acaba fazendo com que essa memória esteja relacionada a uma forma de supremacia ideológica, por meio da qual "seus praticantes estão tentando obrigar alguém a acreditar em algo, havendo ou não boas evidências para isso." (MCINTYRE, 2018, p. 12). ${ }^{17}$ Aqui é importante fazer uma ressalva. Não se trata de dizer que as agências tentam a todo custo fazer com que as pessoas nelas acreditem. Trata-se, antes, de reconhecer uma dinâmica em que as agências se colocam (ou são colocadas) num lugar de objetividade profissional que nem sempre lhe cabe, conforme demonstram Komesu, Alexandre e Silva (2020, p. 222), segundo os quais as agências, na pretensão de serem transparentes, "ignoram constrições sócio-históricas das práticas discursivas que as constituem.".

Portanto, a "obrigação para crer" (frequente na posição enganosa) e a "sedução para desmentir" (frequente na posição institucional) podem ser interpretadas como características não somente das agências de checagem de fatos, como também dos usuários que pretendem buscar a verdade, ou que pretendem deliberadamente causar dano com alguma notícia falsa. Esses

17 Nossa tradução para "its practitioners are trying to compel someone to believe in something whether there is good evidence for it or not". 
pontos de vista coexistem nessas práticas letradas digitais, e a memória discursiva pode ser um conceito importante para compreendermos a emergência desses confrontos, tornando-se importante para a formação do leitor em tempos de pandemia.

\section{Referências}

ACHARD, Pierre. Memória e produção discursiva do sentido. In: ACHARD, Pierre et al. Papel da Memória. Tradução de José Horta Nunes. Campinas, SP: Pontes, 1999.

AUTHIER-REVUZ, Jaqueline. Heterogeneidade(s) enunciativa(s). Caderno de Estudos Linguísticos. Campinas, v. 19, p. 25-42, 1990.

CRYSTAL, David. English as a Global Language. Cambridge: Cambridge University Press, 2003.

DUCROT, Oswald. La polifonía en lingüística. In: DUCROT, Oswald. Polifonía y argumentación. Conferencias del seminário teoria de la argumentacion y analisis del discurso. Cali: Universidad del Valle, p. 15-30, 1988.

FOSSEY, Marcela Franco. Polêmica sobre sexo saudável: uma abordagem discursiva. Tese (Doutorado em Linguística) - Universidade Estadual de Campinas, Instituto de Estudos da Linguagem, 2011.

FOUCAULT, Michel. A ordem do discurso: aula inaugural do Collège de France, pronunciada em 2 de dezembro de 1970. Tradução de Laura Fraga de Almeida Sampaio. 24. ed. São Paulo: Edições Loyola, 2014.

HARARI, Yuval Noah. Yuval Noah Harari: the world after coronavirus. Disponível em https://www.ft.com/ content/19d90308-6858-11ea-a3c9-1fe6fedcca75. The Financial Times, 2020. Acesso em: 05 jul. 2021. 
KOMESU, Fabiana Komesu; ALEXANDRE, Gabriel Guimarães; SILVA, Larissa Souza da. A cura da infodemia? O tratamento da desinformação em práticas sociais letradas de checagem de fatos em tempos de covid-19. In: RODRIGUES, Daniela Lopes Dias Ignácio; SILVA, Jane Quintiliano Guimarães (org.). Estudos aplicados à prática da escrita acadêmica: colocando a mão na massa. Belo Horizonte: Editora PUC Minas, v. 3, p. 186-229, 2020.

LANKSHEAR, Colin; KNOBEL, Michele. New Literacies: Everyday practices and classroom learning. 2. ed. Glasglow: McGraw-Hill. Inglaterra: Open University Press, 2006.

LANKSHEAR, Colin; KNOBEL, Michele. New literacies: everyday practices and social learning. 3. ed. Inglaterra: Open University Press, 2011.

LEWANDOWKY. Stephan et al. Misinformation and its correction continued influence and successful debiasing. Psychological Science in the Public Interest, p. 106131, 2012. Disponível em: https://journals.sagepub.com/ doi/10.1177/1529100612451018. Acesso em: 05 jul. 2021.

LONGHI, Carla Reis. Informação jornalística: da mediação à midiatização. Intercom - RBCC. São Paulo, v. 38, n. 2, p. 185206, jul./dez. 2015.

MAINGUENEAU, Dominique. Gênese dos discursos. Tradução de Sírio Possenti. São Paulo: Parábola Editorial, 2008. MARTENS, Bertin et al. The digital transformation of news media and the rise of disinformation and fake news. JRC Digital Economy Working Paper, 2018. Disponível em https:// ec.europa.eu/jrc/en/publication/eur-scientific-and-technicalresearch-reports/digital-transformation-news-media-and-risedisinformation-and-fake-news. Acesso em: 05 jul. 2021.

MARWICK, Alice; LEWIS, Rebecca. Media Manipulation and Dis-information Online. Data and Society, 2017. Disponível em 
https://datasociety.net/output/media-manipulation-and-disinfoonline. Acesso em: 05 jul. 2021.

MCINTYRE, Lee. Post-Truth. Cambridge, Massachussets: MIT Press, 2018.

MONNERAT, Alessandra. A aposta no fact checking: jornalistas criam mais iniciativas para verificar o discurso público e revelar notícias falsas. Knight Center for Journalism in the Americas, 19 abr. 2017. Disponível em https://www.sjsp.org.br/noticias/aaposta-no-fact-checking-f810. Acesso em: 05 jul. 2021.

NYHAN, Brendan; REIFLER, Jason. Estimating Factchecking's Effects: Evidence from a long-term experiment during campaign. American Press Institute, 2014.

ORLANDI, Eni Puccinelli. Análise de Discurso: princípios e procedimentos. 8. Ed. Campinas: Pontes, 2009.

PAVEAU, Marie-Anne. Memória, des-memória, a-memória: quando o discurso volta-se para seu passado. Tradução de Jocilene Santana Prado; Eduardo Lopes Piris. EID\&A Revista Eletrônica de Estudos Integrados em Discurso e Argumentação. Ilhéus, n. 5, p. 137-161, dez. 2013.

PANGRAZIO, Luci. What's new about "fake news"? Critical digital literacies in an era of fake news, post-truth and clikbait. Revista Páginas de Educación, v. 11, n. 1, p. 6-22, 2018.

PÊCHEUX, Michel. O discurso: estrutura ou acontecimento. Tradução de Eni Pulcinelli Orlandi. Campinas: Pontes, 1990.

PÊCHEUX, Michel. Papel da Memória. In: ACHARD, Pierre et al. Papel da Memória. Tradução de José Horta Nunes. Campinas, SP: Pontes, 1999.

SPINELLI, Egle Müller; SANTOS, Jéssica de Almeida. Jornalismo na era da pós-verdade: fact-checking como ferramenta de combate às fake news. Revista Observatório, v. 4, n. 3, p. 759-782, 2018. 
TANDOC JR., Edson C.; LIM, Zheng Wei; LING, Richard. Defining "Fake News". Digital Journalism, v. 6, n. 2, p. 137153, 2018. Disponível em www.encurtador.com.br/yNSX8. Acesso em: 05 jul. 2021.

WARDLE, Claire; DEREKSHAN, Hossein. Information Disorder: toward an interdisciplinar framework for research and policy making. Council of Europe Report, DGI, 2017. 